\title{
Profiling of circulating microRNA and pathway analysis in normal- versus over-conditioned dairy cows during the dry period and early lactation
}

\author{
Laura A. Webb, ${ }^{1 *}$ Morteza H. Ghaffari, ${ }^{1 *}$ Hassan Sadri, ${ }^{2} \dagger$ Katharina Schuh,,${ }^{1,3}$ Valentina Zamarian, ${ }^{4 *}$ \\ Christian Koch, ${ }^{5}$ Nares Trakooljul, ${ }^{6}$ Klaus Wimmers, ${ }^{6}$ Cristina Lecchi, ${ }^{4}$ Fabrizio Ceciliani, ${ }^{4}$ \\ and Helga Sauerwein ${ }^{1} \ddagger$ \\ ${ }^{1}$ Institute of Animal Science, Physiology Unit, University of Bonn, 53115 Bonn, Germany \\ ${ }^{2}$ Department of Clinical Science, Faculty of Veterinary Medicine, University of Tabriz, 5166616471 Tabriz, Iran \\ ${ }^{3}$ Department of Life Sciences and Engineering, Animal Nutrition and Hygiene Unit, University of Applied Sciences Bingen, \\ 55411 Bingen am Rhein, Germany \\ ${ }^{4}$ Dipartimento di Medicina Veterinaria, Università di Milano, 20133 Milano, Italy \\ ${ }^{5}$ Educational and Research Center for Animal Husbandry, Hofgut Neumuehle, 67728 Muenchweiler an der Alsenz, Germany \\ ${ }^{6}$ Leibniz-Institute for Farm Animal Biology (FBN), Institute for Genome Biology, 18196 Dummerstorf, Germany
}

\begin{abstract}
The objective of this study was to determine the circulating microRNA (miRNA) profile in over-conditioned (HBCS) versus normal-conditioned (NBCS) dairy cows in combination with pathway enrichment analyses during the transition period. Thirty-eight multiparous Holstein cows were selected 15 wk before anticipated calving date based on their current and previous body condition scores (BCS) for forming either a HBCS group $(\mathrm{n}=19)$ or a NBCS group $(\mathrm{n}=19)$. They were fed different diets during late lactation to reach the targeted differences in BCS and backfat thickness until dry-off. A subset of 15 animals per group was selected based on their circulating concentrations of nonesterified fatty acids (on d 14 postpartum) and $\beta$-hydroxybutyrate (on d 21 postpartum), representing the greater or the lower extreme values within their BCS group. Blood serum obtained at d -49 and 21 relative to parturition ( 3 pools with 5 cows per each group and time point) were used to identify miRNA that were differentially expressed (DE) between groups or time points using miRNA sequencing. No DE-miRNA were discovered between NBCS versus HBCS. Comparing pooled samples from d -49 and $\mathrm{d} 21$ resulted in 7 DE-miRNA in the NBCS group, of which 5 miRNA were downregulated and 2 miRNA were overexpressed on d 21 versus -49 . The abundance of 5 of these DE-miRNA was validated in all individual

Received January 30, 2020.

Accepted June 7, 2020.

*These authors contributed equally to this work.

$\dagger$ H. Sadri was a visiting scientist at the Institute of Animal Science, Physiology Unit, University of Bonn, Bonn, Germany at the time this research was done.

‡Corresponding author: sauerwein@uni-bonn.de
\end{abstract}

samples via quantitative PCR and extended to additional time points $(\mathrm{d}-7,3,84)$. Group differences were observed for miR-148a, miR-122 as well as miR-455-5p, and most DE-miRNA (miR-148a, miR-122, miR-30a, miR-450b, miR-455-5p) were downregulated directly after calving. Subsequently, the DE-miRNA was used for bioinformatics analysis to identify putative target genes and the most enriched biological pathways. The most significantly enriched pathways of DE-miRNA were associated with cell cycle and insulin signaling as well as glucose and lipid metabolism. Overall, we found little differences in circulating miRNA in HBCS versus NBCS cows around calving.

Key words: body condition, bioinformatics, microRNA, transition cows

\section{INTRODUCTION}

Reproduction and lactation are processes that are naturally prioritized in nutrient partitioning, with the onset of lactation requiring comprehensive metabolic and physiological adaptations. In high-yielding dairy cows, this adaptation is particularly challenging because nutrient intake is usually insufficient during lactation, leading to a negative energy balance (NEB; Grummer, 1995; Drackley et al., 2005). Body reserves, mainly adipose tissue (but also skeletal muscle), are mobilized to meet the elevated energy demands. Both the rate and extent of tissue mobilization are thereby controlled by different factors such as BCS at calving, diet composition, and milk yield (Komaragiri et al., 1998). Cows that are over conditioned around calving usually experience a more pronounced and prolonged NEB and greater tissue mobilization when compared with animals in normal or lean condition (Reid et al., 1986; Roche et al., 2009; Pires et al., 2013). Consequently, over-conditioned cows are at greater risk for 
developing metabolic disorders, such as fatty liver or ketosis, and may experience other health issues, all of which can compromise productivity (Gearhart et al., 1990; Drackley et al., 2005; Ingvartsen, 2006). The effect of over conditioning around calving on different blood metabolites (Mansouryar et al., 2018; Schuh et al., 2019) and circulating lipid intermediates (Rico et al., 2015), as well as metabolic pathways at the metabolome (Ghaffari et al., 2019; Ghaffari et al., 2020a) and proteome level (Ghaffari et al., 2020b) were previously demonstrated. However, the effects of over conditioning on metabolic pathways at the microRNA (miRNA) level are still not well understood.

MicroRNA are small noncoding RNA molecules of 18 to 25 nucleotides that regulate gene expression at the posttranscriptional level, causing RNA degradation or blocking of mRNA translation (Bartel, 2004). They are stable in various body fluids, including blood serum or plasma, and may carry signatures specifically related to the pathophysiological status (Coenen-Stass et al., 2015). In addition to cancer, various metabolic disorders, including obesity (Manning et al., 2019), diabetes (Chen et al., 2008), liver injury (Laterza et al., 2009), metabolic syndrome (Huang et al., 2018), and muscular dystrophy (Mizuno et al., 2011), have been associated with altered profiles of circulating miRNA in humans. Moreover, as miRNA may be selectively secreted, it has been hypothesized that they might function on a hormone-like basis, regulating cellular communication across different tissues (Coenen-Stass et al., 2015). Recently, Ylioja et al. (2019) evaluated the association between BCS in the week before parturition and the miRNA profile in colostrum. The slight differences in colostrum miRNA of cows with either high BCS $(\geq 4.0$ on a scale of 1-5) or moderate BCS (2.75-3.50) were identified; the presence of several miRNA in colostrum indicates an important role for both the lactating cow and the neonate.

The putative relevance of cell-free circulating miRNA has scarcely been investigated in dairy cows and, to our knowledge, miRNA studies addressing the transition period related to BCS status are entirely lacking. Furthermore, the identification of miRNA associated with over-conditioning around calving may help to elucidate the mechanisms involved in the pathophysiology of transition cows. We hypothesized that over conditioning around calving would affect the profile of circulating miRNA. Therefore, we used an animal model of normal condition versus over condition around calving based on a targeted divergence in body condition in late lactation (Schuh et al., 2019). We aimed to identify the miRNA from serum that is differentially expressed (DE) by sequencing and to validate and profile those DE-miRNA from 7 wk before calving until 12 wk post- partum in over-conditioned versus normal-conditioned cows by quantitative (q)PCR.

\section{MATERIALS AND METHODS}

The animal experiment was performed at the Educational and Research Center for Animal Husbandry (Hofgut Neumuehle, Muenchweiler a.d. Alsenz, Germany) according to the German Animal Welfare Act and approved by the local authority for animal welfare affairs [Landesuntersuchungsamt Rheinland-Pfalz, (G 14-20-071)] Koblenz, Germany.

\section{Animals, Treatments, and Experimental Design}

A detailed description of the study design with the performance results was presented by Schuh et al. (2019) and is depicted in Figure 1A. In brief, $15 \mathrm{wk}$ before expected calving date, 38 multiparous German Holstein cows (parity $2.9 \pm 0.3$, mean \pm SD) were allocated to either a normal-conditioned (NBCS; $\mathrm{n}=19$ ) or high-conditioned (HBCS; $\mathrm{n}=19$ ) group. To reach the targeted differences in BCS and backfat thickness $($ BFT) in the experimental groups (NBCS: BCS $<3.5$ and $\mathrm{BFT}<1.2 \mathrm{~cm}$; HBCS: BCS $>3.75$ and BFT $>$ $1.4 \mathrm{~cm}$ ) until dry-off (wk 7 ante partum; AP), NBCS cows received a low-energy ration $\left(6.8 \mathrm{MJ}\right.$ of $\mathrm{NE}_{\mathrm{L}} / \mathrm{kg}$ of DM) and HBCS cows were fed a ration with greater energy density (7.2 $\mathrm{MJ}$ of $\mathrm{NE}_{\mathrm{L}} / \mathrm{kg}$ of $\left.\mathrm{DM}\right)$ during late lactation. The diets were balanced according to the recommendations of the Society for Nutrition Physiology (GfE, 2001). During the dry period and the subsequent lactation, both groups received the same diets. At dry-off, the NBCS cows had a BCS $<3.5$ (minimum value 2.75 ) and a $B F T<1.2 \mathrm{~cm}$ (minimum value 0.58 ), whereas the HBCS cows had a BCS $>3.75$ (maximum value 4.50 ) and a $B F T>1.4 \mathrm{~cm}$ (maximum value 2.90; Figure 1B). A subset of 30 animals (3 pools with 5 cows per each time point and group) was subjected to miRNA sequencing for identifying miRNA that were DE [false discovery rate $(\mathbf{F D R}) \leq 0.05$ and mean read count $\geq 200$ normalized reads] between groups or time points. The subsets were selected from a total of 38 cows based on their circulating concentrations of nonesterified fatty acids (NEFA) and BHB on d 14 and 21 postpartum (PP), respectively. Cows with the upper extreme values in the HBCS group formed the HBCS subset group $(\mathrm{NEFA}=0.8 \pm 0.4 \mathrm{mmol} / \mathrm{L}$, $\mathrm{BHB}=1.8 \pm 0.4 \mathrm{mmol} / \mathrm{L}$; means $\pm \mathrm{SD}$ ), whereas the cows with the lower extreme values within the NBCS subset group made the NBCS group (NEFA $=0.5 \pm$ $0.3 \mathrm{mmol} / \mathrm{L}, \mathrm{BHB}=1.0 \pm 0.2 \mathrm{mmol} / \mathrm{L}$; Figure $1 \mathrm{~B})$.

Both BCS and BFT were continuously monitored every 2 wk during the entire trial (from wk 15 AP to wk 
$12 \mathrm{PP})$. The BCS was estimated on a 5 -point scale with 0.25 increments $(1=$ emaciated, $5=$ extremely fat; Edmonson et al., 1989), whereas BFT was assessed using ultrasonography (Agroscan L, ALR 500, 5-MHz lineararray transducer, Echo Control Medical, Angoulême, France) as described by Schröder and Staufenbiel (2006). From wk 7 AP until wk 12 PP, blood was collected weekly from the coccygeal vein after milking but before providing fresh feed. Blood samples were stored at room temperature until coagulated (maximum of 60 $\min )$, centrifuged for $10 \mathrm{~min}$ at 2,000 $\times \mathrm{g}$, and then stored at $-80^{\circ} \mathrm{C}$ until analysis. The miRNA sequencing (Figure 1C) was conducted using the 2 time points on $\mathrm{d}-49$ and 21 relative to parturition. The validation of candidate miRNA using qPCR was conducted using the 5 time points on $\mathrm{d}-49,-7,3,21$, and 84 relative to parturition, and included 30 out of 38 (based on NEFA and BHB) animals.

\section{miRNA Extraction, Library Construction, and Sequencing}

Total RNA was extracted from $200 \mu \mathrm{L}$ of serum using the Qiagen miRNeasy serum/plasma kit (Qiagen, Milan, Italy). One milliliter of Qiazol (Qiagen) was added, incubated at room temperature for $5 \mathrm{~min}$, and then the exogenous Caenorhabditis elegans miRNA cel-miR-39 spike-in control (Qiagen) was added, according to the manufacturer's instructions. To ensure complete mixing, samples were thoroughly vortexed and then RNA extraction was carried out according to the manufacturer's instructions. The quality and quantity of small
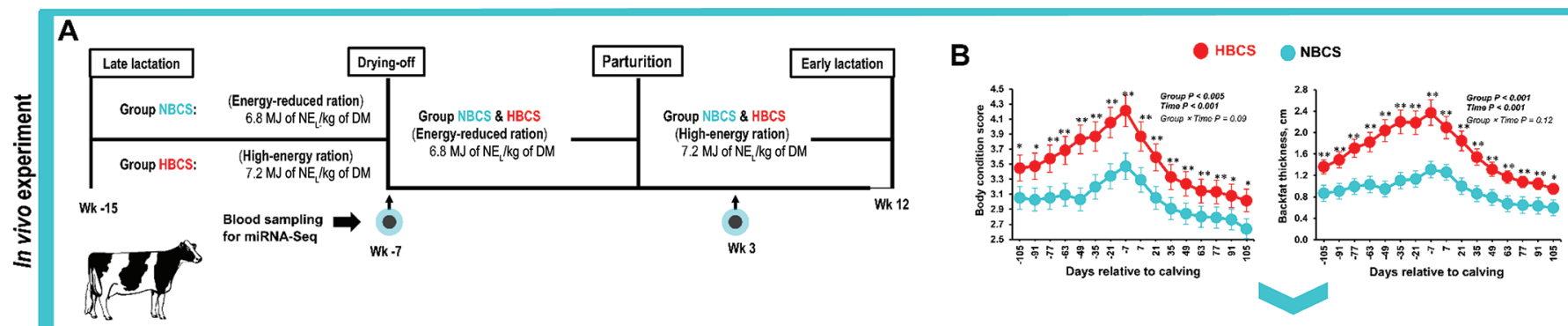

Animals $(n=30)$ were divided into pools ( 3 pools with 5 cows each per time point and group) based on the high or low extreme values of NEFA (d 14 pp) and BHB (d 21 pp)
$4.50<B C S>3.75 \cdot$ NEFA $=0.8 \pm 0.4 \mathrm{mmol} / \mathrm{BHB}=1.8 \pm 0.4 \mathrm{mmol} / \mathrm{L} \cdot \mathrm{means} \pm \mathrm{SD}$

C

MicroRNA sequencing

NBCS: $3.50<B C S>2.75$. NEFA $=0.5 \pm 0.4$

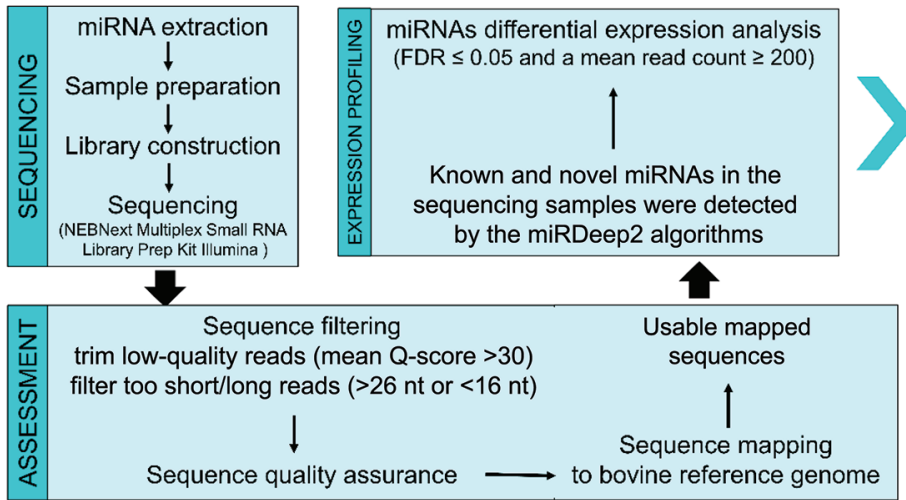

Known and novel miRNAs in the uencing samples were detected

sable mapped quences

Sequence mapping o bovine reference genome

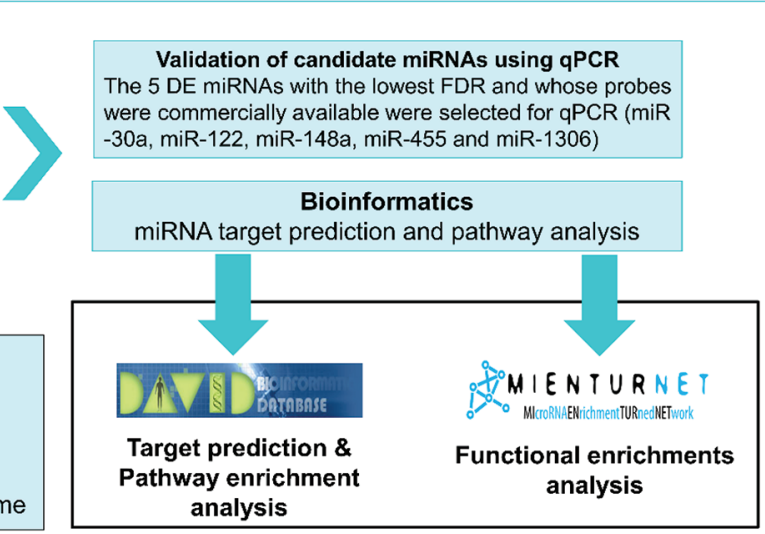

Figure 1. Schematic diagram of the study and workflow. (A) The timeline of the study period was from 15 wk before expected calving date (ante partum) until $12 \mathrm{wk}$ after calving (postpartum). Arrows indicate blood sampling time points. (B) Changes of BCS and backfat thickness (BFT) of over- (HBCS; > 3.75 BCS and $>1.4 \mathrm{~cm} \mathrm{BFT)} \mathrm{and} \mathrm{normal-conditioned} \mathrm{(NBCS;}<3.5$ BCS and $<1.2 \mathrm{~cm}$ BFT) cows during the experimental period. Data for BCS and BFT $(\mathrm{n}=19$ per group) are from Schuh et al. $(2019)$. Different letters indicate differences $(P<0.05)$ between the time points in the HBCS $(\mathrm{A}-\mathrm{C})$ and in the NBCS $(\mathrm{a}-\mathrm{c})$ groups, respectively. Asterisks indicate a difference $(* P<0.05 ; * * P<0.01)$ between groups at a given time point. Data are presented as means \pm SEM. Subsets of animals (3 pools with 5 cows each per time point and group) were subjected to microRNA (miRNA) sequencing for identifying miRNA that were differentially expressed [false discovery rate (FDR) $\leq 0.05$ and mean read count $\geq 200]$ between groups or time points. A total of 30 cows were selected based on their circulating concentrations of nonesterified fatty acids (NEFA) and BHB on d 14 and d 21 postpartum, respectively: cows with the upper extreme values in the HBCS group formed the HBCS group (NEFA $=0.8 \pm 0.4 \mathrm{mmol} / \mathrm{L}, \mathrm{BHB}=1.8 \pm 0.4 \mathrm{mmol} / \mathrm{L}$, means $\pm \mathrm{SD}$ ), whereas the cows with the lower extreme values within the NBCS group made the NBCS group (NEFA $=0.5 \pm 0.3 \mathrm{mmol} / \mathrm{L}, \mathrm{BHB}=1.0 \pm 0.2 \mathrm{mmol} / \mathrm{L}$ ). (C) Procedure summary for miRNA sequencing and bioinformatics. 
RNA was assessed using an Agilent Small RNA kit on a 2100 Bioanalyzer (Agilent Technologies, Waldbronn, Germany). Samples were then pooled (3 pools with 5 individuals per group and day) and libraries were prepared with a NEBNext Multiplex Small RNA Library Prep Kit for Illumina (New England BioLabs GmbH, Frankfurt, Germany) according to the manufacturer's recommendations.

\section{Detection and Expression Profiling of miRNA}

The base call files from the sequencing run were demultiplexed and converted into FASTQ files using the bcl2fastq2 conversion software, version 2.19 (Illumina). The FASTQ-formatted sequence data were qualitychecked using FastQC version 0.11.5 (Babraham Bioinformatics, 2018). The libraries were size-selected and purified using PAGE. The quality of the libraries was assessed using the Highly Sensitive DNA assay and a 2100 Bioanalyzer (Agilent). A total of 12 multiplexed libraries were parallel sequenced for single-end of $50 \mathrm{bp}$ using the rapid-run mode of the Illumina HiSeq 2500 system by the sequencing facility of the Genome Biology Institute, FBN, Dummerstorf, Germany. The detection and expression profiling of miRNA was performed using the miRDeep2 software package (Mackowiak, 2011; Friedländer et al., 2012). Briefly, the preprocessed highquality reads [by trimming low-quality reads (mean Q-score $<30$ ) and filtering too-short or too-long reads $(>26$ or $<16$ nucleotides)] were aligned to the bovine reference genome assembly Bos_taurus_UMD3.1 using mirDeep2. Known and novel miRNA in the sequencing samples were detected by the miRDeep2 algorithms based on secondary structure positional alignment such as positional alignment, secondary RNA structure, entropy, and biogenesis-based model as well as the reference of bovine miRNA and conserved miRNA cross-species (human and mouse) from miRBase version 21. Differential expression analysis of miRNA was done using edgeR (Robinson et al., 2010; McCarthy et al., 2012). The DE-miRNA were defined by an adjusted FDR $\leq 0.05$ and a mean read count $\geq 200$. Novel miRNA were excluded from further analysis.

\section{Validation of Candidate miRNA Using qPCR}

To validate the results of sequencing, the expression of DE-miRNA was quantified in sequenced samples and was extended to individual samples and additional time points $(-7,3$, and $84 \mathrm{~d}$ relative to parturition) by reverse transcription (RT) qPCR. The RT was performed with $2 \mu \mathrm{L}$ of serum total-RNA per reaction using the TaqMan Advanced miRNA cDNA Synthesis
Kit (Applied Biosystems, Monza, Italy) according to the manufacturer's protocol.

The 5 DE-miRNA with the lowest FDR and probes that were commercially available were selected for qPCR. The probes included cel-miR-39-3p (assay 478293_mir), hsa-miR-30a-3p (assay 478273_mir), rno-miR-122-5p (assay rno480899_mir), hsa-miR-1483p (477814_mir), hsa-miR-455-5p (assay 478113_mir), and hsa-miR-1306-5p (assay 478701_mir). The qPCR was performed in a scale-down reaction volume $(12 \mu \mathrm{L})$ on an Eco Real-Time PCR detection system (Illumina, San Diego, CA) using $6 \mu \mathrm{L}$ of $2 \times$ TaqMan Fast Advanced Master Mix, $0.6 \mu \mathrm{L}$ of $20 \times$ miRNA specific TaqMan Advance assay, $1 \mu \mathrm{L}$ of cDNA, and RNasefree water to reach the volume. The cycling program was $50^{\circ} \mathrm{C}$ for $2 \mathrm{~min}, 95^{\circ} \mathrm{C}$ for $3 \mathrm{~min}$, and 40 cycles of $95^{\circ} \mathrm{C}$ for $10 \mathrm{~s}$ and $60^{\circ} \mathrm{C}$ for $30 \mathrm{~s}$. To reduce technical variation, a reference sample was loaded on each plate. The expression levels of serum miRNA were normalized to cel-miR-39 using the $2-{ }^{\Delta \Delta \mathrm{Ct}}$ method (Livak and Schmittgen, 2001).

\section{Statistical Analysis}

Differences between treatments and time were tested using a repeated mixed model procedure of SPSS (IBM SPSS Statistics 24, Armonk, NY) with Bonferroni correction for multiple comparisons. Group, time (sampling day), and the interaction thereof were used as fixed factors, and "cow" was considered as a random factor. Additionally, time was set as a repeated measurement. The level of significance was set at $P \leq$ 0.05 and trends were considered at $0.05<P \leq 0.10$. Relationships between variables were tested by Spearman correlation. The graphical representation was given by the R package "Corrplot" (Friendly, 2002). The residuals of each parameter were tested for normal distribution. For performing mixed model analyses, data were transformed by a 2-step approach (Box-Cox transformation). All figures were generated with the nontransformed data (means \pm SEM).

\section{miRNA Target Prediction and Pathway Analysis}

The pathway enrichment analysis was performed using miRNet tool (Fan et al., 2016), an easy-to-use comprehensive tool integrating data from 11 different miRNA databases (TarBase, miRTarBase, miRecords, miRanda, miR2Disease, HMDD, PhenomiR, SM2miR, PharmacomiR, EpimiR, and starBase), as well as human miRNA accession numbers of miRbase (Figure 1C). To predict potential target genes of DE-miRNA, both miRNet and Kyoto encyclopedia of genes and genomes 
(KEGG) databases (https://www.genome.jp/kegg) were used. Exploring the entire role of the DE-miRNA based on validated targets, we used DIANA-miRPath version 3.0 (http://mirnatools.eu). This tool allows for analyzing KEGG molecular pathways and gene ontology at 3 different levels: biological processes (BP), molecular function (MF), and cellular component (CC). The TarBase tool was selected for the generation of the heatmap and corrected for the FDR by the BenjaminiHochberg procedure for miRNA associated with KEGG pathways as described by Vlachos et al. (2015).

\section{Functional Enrichment Analysis}

The MIENTURNET (MicroRNA ENrichment TURned NETwork) web tool was implemented by using the $\mathrm{R}$ programming language (release 3.4.4, March 2018) for the functional enrichment analysis provided by reactome and KEGG databases (http://www.rproject .org; Figure 1C). Predicted significant DE-miRNA targets were computationally obtained from the TargetScan database (http://www.targetscan.org/vert -71/), and genes with cumulative weighted context ++ scores $<-0.4$ were further analyzed. The TargetScan predicts biological targets of miRNA by searching for the presence of conserved sites that match the seed region (i.e., the region comprising nucleotides $2-7$ at the $5^{\prime}$ end of the mature miRNA sequence) of each miRNA (Lewis et al., 2005). The functional enrichment results of miRNA with interaction in their target genes were visualized by the clusterProfiler package of $\mathrm{R}$ software (Yu et al., 2012).

\section{RESULTS}

\section{miRNA Sequencing Data}

Serum miRNA were sequenced to identify DE-miRNA in HBCS versus NBCS cows at d -49 and 21 relative to parturition. In total, 709 miRNA identities, of which 289 were annotated as Bos taurus miRNA (bta-miR) were detected. Figure 2 shows the most abundant btamiR found in serum pools of dairy cows at $d-49$ and 21 relative to parturition.

\section{Validation of Sequencing Results and Quantification of DE-miRNA}

No DE-miRNA were identified between NBCS d 21 versus HBCS d 21, HBCS d -49 versus HBCS d 21, and NBCS d -49 versus HBCS d -49 . Comparing pooled samples from NBCS d -49 and NBCS d 21 resulted in 7 DE-miRNA, of which 5 miRNA [miR-148a, miR-122, miR-30a, miR-450b, miR-455-5p] were downregulated
(1.1- to 1.7-fold), and 2 miRNA [miR-16b and miR1306] were overexpressed (1.2-fold, $P \leq 0.05)$ in the NBCS 21 versus NBCS -49 groups, respectively.

The sequencing results were validated using 6 out of 7 DE-miRNA, and their relative abundance was quantified using the spike in cel-miR-39 for normalization. The selected miRNA targets were detected in all samples except for bta-miR-450b. Regardless of the animals' body conditions, the abundance of all 5 DE-miRNA showed almost similar patterns (Figure 3) with decreases toward calving $(\mathrm{d}-7 / \mathrm{d} 3)$ and increases thereafter $(P<0.05)$. Time effects were significant for miR-148a (Figure 3A; $P<0.01$ ), miR-122 (Figure 3B; $P<0.01$ ), miR-30a (Figure 3C; $P<0.01$ ), miR-1306 (Figure 3B; $P<0.01$ ), and miR-455-5p (Figure 3E; $P=0.02)$. For miR-148a, NBCS cows had a 1.4-fold greater expression at $\mathrm{d}-49(P=0.02)$ and a trend for higher expression at d 3 (1.4-fold; $P=0.09$ ) compared with HBCS cows. At d 21, miR-148a tended to be upregulated in HBCS cows relative to NBCS cows (1.2-fold; $P=0.08)$. Group differences were observed for miR-148a, miR-122, and miR-455-5p $(P<0.05)$ with mostly parallel changes. As compared with HBCS cows, the abundance of miR-122 and miR-455-5p in the serum of NBCS cows was 1.3-fold higher at $\mathrm{d}-49(P=$ $0.03)$ and 1.9 -fold higher at $\mathrm{d} 3(P=0.01)$, respectively.

\section{Associations Between DE-miRNA}

Spearman's correlation analysis was applied to assess the relationship between the different miRNA from $\mathrm{qPCR}$ results (Figure 4). Regardless of group and time (Figure 4A), strong positive correlations were observed for miR-30a with miR-122 and miR-455-5p,

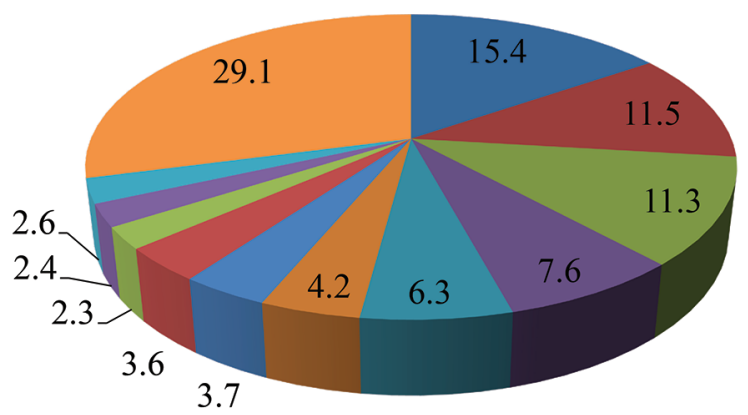

\begin{tabular}{|c|c|c|}
\hline bta-miR-486 & - bta-miR-122 & - bta-miR-423-5p \\
\hline -miR-30d & — bta-miR-21-5p & bta-miR-191 \\
\hline R-192 & bta-miR-25 & bta-miR-148a \\
\hline$a-m i R-10 b$ & ata-miR-23a & all other bta-miR \\
\hline
\end{tabular}

Figure 2. Portion of target Bos taurus microRNA (bta-miR) $\geq 2 \%$ of all bta-miR found in serum pools of dairy cows at $d-49$ and 21 relative to parturition. Values are given as percentages of total bta-miR. 
A miR-148a

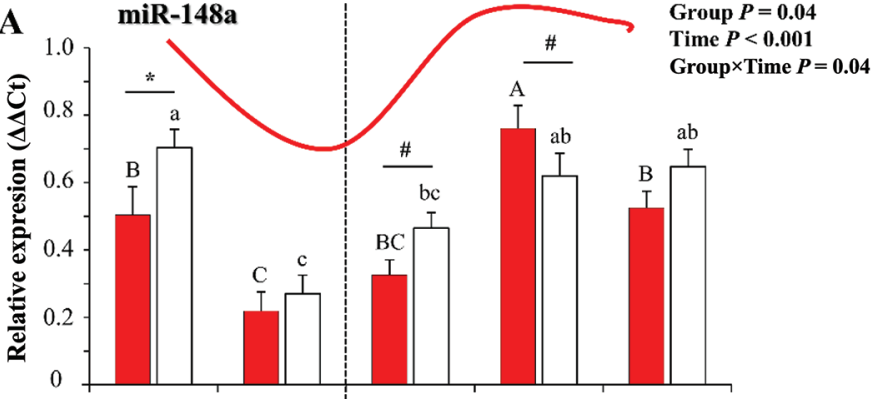

$-49$

B

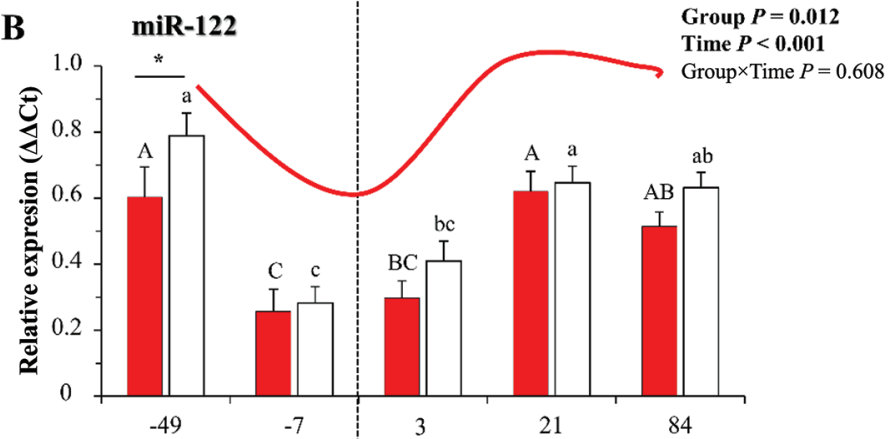

C

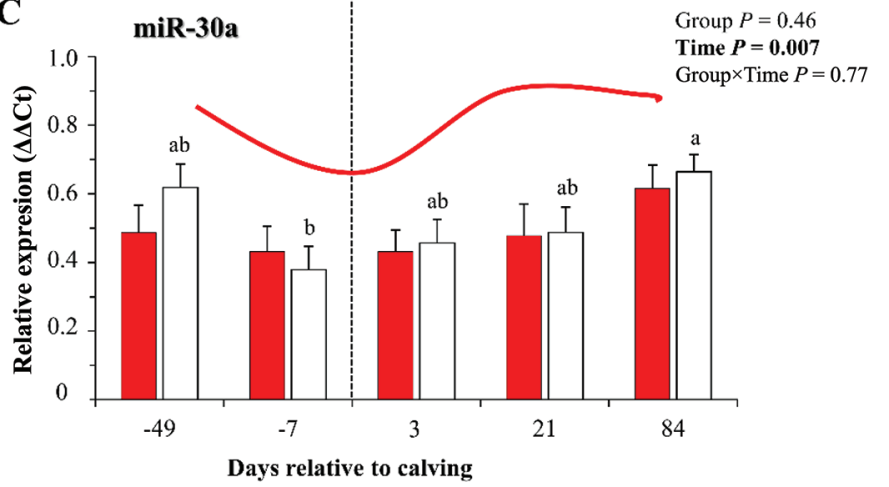

D

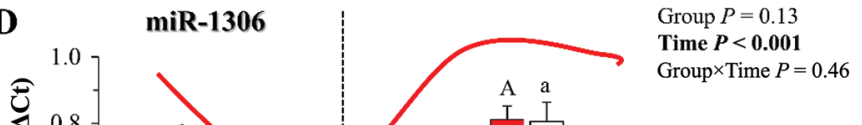

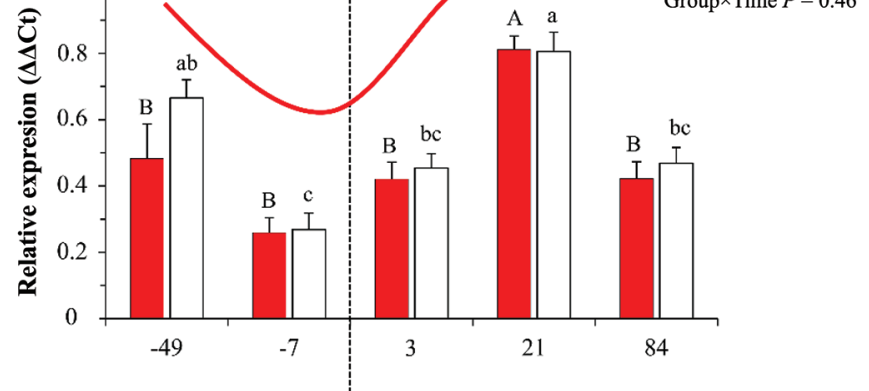

$\mathbf{E}$

miR-455-5p
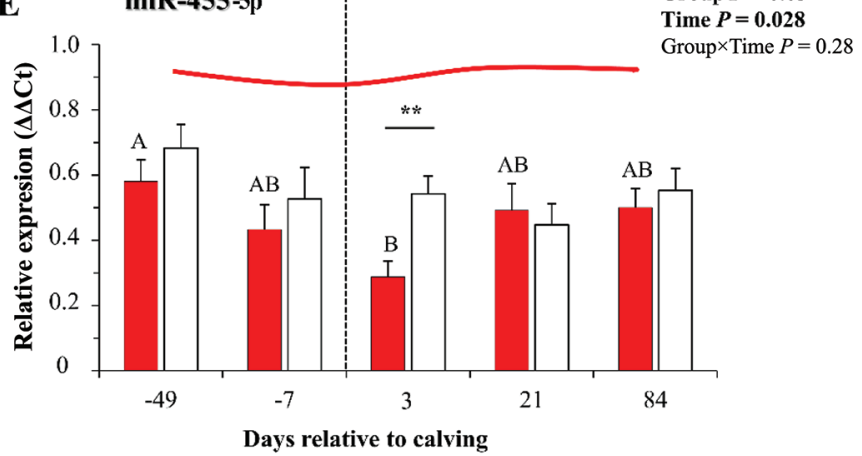

- HBCS

NBCS

Figure 3. Relative abundance of serum microRNA (miRNA) as assessed by quantitative PCR in high (HBCS; $\mathrm{n}=15)$ and normal body condition (NBCS; $\mathrm{n}=15$ ) dairy cows on $\mathrm{d}-49,-7,3,21$ and 84 relative to parturition. Data are given as means \pm SEM. Different uppercase letters $(\mathrm{A}-\mathrm{C})$ illustrate differences $(P<0.05)$ between time points within HBCS. Different lowercase letters $(\mathrm{a}-\mathrm{c})$ illustrate differences $(P<$ $0.05)$ between time points within NBCS. Differences between HBCS and NBCS within 1 time point are labeled with $*(0.01<P<0.05)$ or $* *$ $(P<0.01)$. Trends $(0.05<P<0.1)$ are labeled with hashtags $(\#)$. The dashed line indicates calving.

and moderate correlations for miR-148a with miR-30a and miR-122. Also, miR-1306 was moderately correlated with miR-148a. When splitting the data set into groups, the correlations of the aforementioned miRNA were consistently stronger for NBCS cows (Figure 4B) compared with HBCS cows (Figure 4C). For instance, the correlation of miR-455-5p with miR-122 was $\mathrm{r}=$ 0.75 in NBCS cows, but only $\mathrm{r}=0.47$ in HBCS cows $(P<0.05)$.

\section{miRNA Target Genes and Pathway Enrichment}

Predicted significant DE-miRNA targets were retrieved from the miRNet and KEGG databases, identifying 1,718 potential target genes. The top 15 significantly enriched KEGG pathways involving those target genes are outlined in Figure 5 (with the pathways related to cancer removed), with cell cycle, insulin signaling, FoxO signaling, phosphatidylinositol 3-kinase $(\mathrm{PI} 3 \mathrm{~K}) /$ protein kinase B (AKT) signaling, and transforming growth factor (TGF)- $\beta$ signaling as the top 5 pathways. The list of enriched genes is reported in Supplemental Table S1 (https://doi.org/ 10.3168/jds.2020-18283). The cell cycle and insulinsignaling pathways and their engaged genes in enrichment analysis are depicted in Supplemental Figures S1 and S2 (https://doi.org/10.3168/jds.2020-18283), respectively. 
Figure 6 shows the heat maps of significant DEmiRNA and the relative KEGG activated pathways at 3 levels: BP (Figure 6A), MF (Figure 6B), and CC (Figure $6 \mathrm{C}$ ). The miRNA versus gene-ontology categories heatmap displays the various molecular functions controlled by the 5 DE-miRNA (miR-122, miR-30a, miR-1306, miR-148a, miR-455-5p). The heatmaps show similar levels of enrichments for most of the DEmiRNA on the cellular nitrogen-compound metabolic process at the $\mathrm{BP}$ level, ion binding at the MF level, and organelle at the CC level. For miR-30a and miR122, particular enrichment was observed for potential regulatory functions in BP.

\section{Functional Enrichment Analysis}

The resulting miRNA-target interactions are visualized as a network in Figure 7. Among the DE-miRNA, target interactions among miR-122, miR-30a, and miR455-5p with at least 2 target interactions were identified. Predicted significant DE-miRNA targets that were computationally obtained from the TargetScan database (http://www.targetscan.org/vert_71/) were further analyzed. The results of the functional enrichment analysis following annotation databases (KEGG and Reactome) are presented in Figure 8. The dot plots show the enrichment of KEGG (Figure 8A) and Reactome pathways (Figure 8B) for 3 DE-miRNA (miR122, miR-30a, and miR-455-5p) with miRNA-target interactions. The miR-122 was mainly involved in glucose metabolism (glycolysis, glycogenesis, fructose, and mannose metabolism), arginine and proline, and
AA biosynthesis as well as collagen formation. The miR-30a was mainly involved in the regulation of actin cytoskeleton, inositol phosphate metabolism, and phosphatidylinositol signaling system. The miR-455-5p was predominantly involved in insulin resistance, interleukin-6 signaling, as well as leptin, adiponectin, and prolactin signaling pathways. For miR-122 and miR455-5p, no overlapping pathways were found, whereas miR-30a had some overlaps with both miR-122 and miR-455-5p, albeit with fewer genes in the respective categories and greater $P$-values.

\section{DISCUSSION}

MicroRNA are recognized as key posttranscriptional regulators of gene expression in multiple BP (Bartel, 2004). Evidence to date suggests that miRNA negatively regulate their target mRNA by partially or completely pairing with their $3^{\prime}$ untranslated region (posttranscriptionally) and by subsequently inducing mRNA degradation (Lim et al., 2005; Esau et al., 2006). To characterize the changes in circulating miRNA during the transition period via sequencing, we used serum of 2 subsets of cows that were selected out of 2 groups with either normal or high BCS based on their NEFA and BHB serum concentrations in early lactation. As reported earlier, the over-conditioned cows were metabolically more challenged during early lactation than the cows with normal body condition due to their greater mobilization of body fat, as evidenced by increased NEFA and BHB concentrations (Schuh et al., 2019). The goals of this study were to characterize the

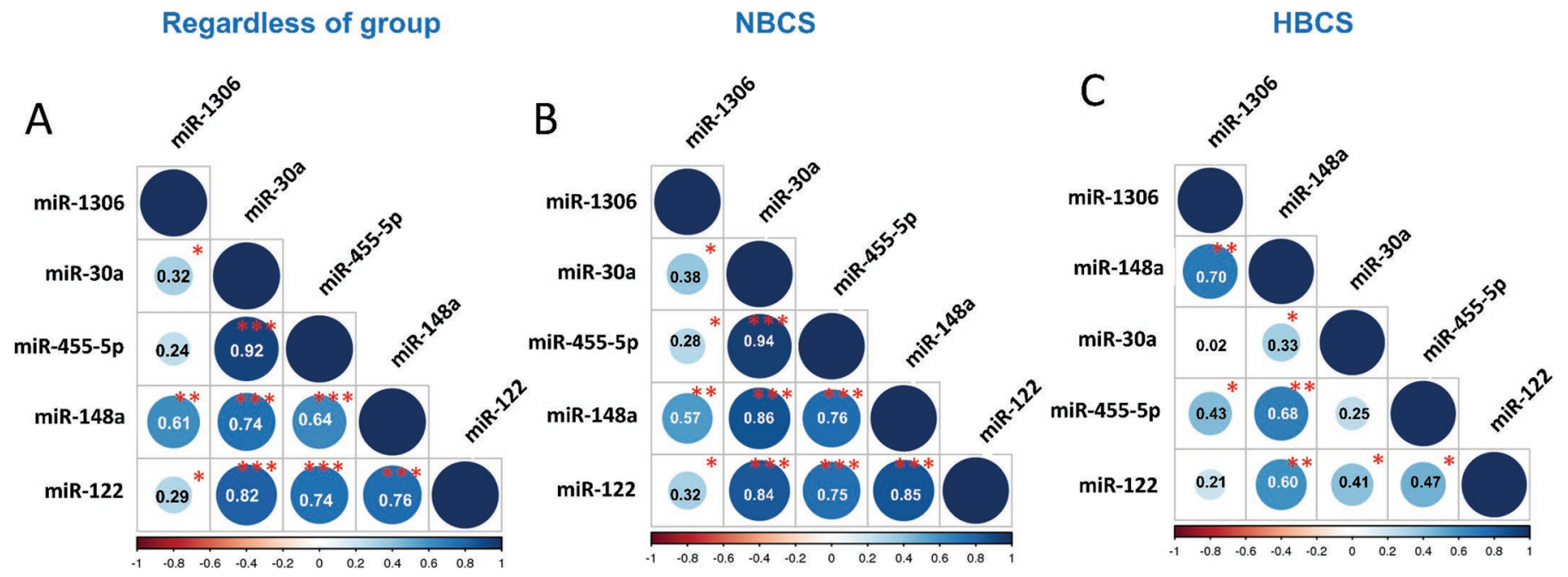

Figure 4. Correlation matrix displaying the positive (blue) and negative (red) correlations between the microRNA (miRNA): (A) regardless of the group, (B) in NBCS, and (C) in HBCS cows. Color and size variation of circles in the figure are proportional to the level of the correlation between traits. The $P$-values with stars indicatie significance at the levels ${ }^{*} P<0.05,{ }^{* *} P<0.01$, and ${ }^{* * *} P<0.001$. NBCS $=$ normal BCS; HBCS = high BCS. 
serum miRNA signatures of periparturient cows and to integrate miRNA to their target genes and relative BP. We adopted a multistep approach, using a microRNA omics (miRNomics) approach as a first step to identify DE-miRNA in serum, then validated miRNA profiling results using $\mathrm{qPCR}$.

The qPCR validation of 5 DE-miRNA (miR-122, miR-30a, miR-1306, miR-148a, miR-455-5p) reported herein confirmed that the DE rate in the serum before and after calving was significant. In the current study, no DE-miRNA were discovered between NBCS versus HBCS based on miRNA sequencing results, but validation with qPCR demonstrated that 3 out of 5 DE-miRNA (miR-122, miR-148a, miR-455-5p) were significantly different between HBCS and NBCS cows. In contrast to the pooled samples used in the sequencing analysis, we assayed individual samples $(\mathrm{n}=15$ per group) and included additional time points (d -7 , 3 , and 84 relative to parturition) for the qPCR validation; therefore, the use of different samples and sample numbers included in each miRNA seq and qPCR likely accounted for the differences in the results of the statistical comparisons. Moreover, comparing pooled samples from NBCS before and after calving resulted in 7 DE-miRNA, of which circulating concentrations of 5 miRNA showed almost similar patterns with decreases toward calving ( $\mathrm{d}-7$ and 3$)$ and increases thereafter. It is well-documented that high-yielding dairy cows may experience metabolic stress as a result of the suboptimal transition from late pregnancy to early lactation
(Roche et al., 2009; 2013). This is mainly characterized by severe NEB, a massive mobilization of body reserves, inflammation, and oxidative stress (Roche et al., 2009, 2013; Ghaffari et al., 2019).

Recently, 2 studies have emerged reporting various DE-miRNA in follicular fluid of cows differing in metabolic status (Hailay et al., 2019) and colostrum of cows differing in BCS (Ylioja et al., 2019). However, with the exception of miR-122 and miR-1306 (as stated by Hailay et al., 2019), there was no overlap with the DEmiRNA in our case. The dissimilarities between these studies are likely attributable to the different body fluids tested. Thus far, we are not aware of any other works on circulating miRNA profiles in cows of different energy or BCS statuses.

In the present study, KEGG analysis revealed that the DE-miRNA were mostly enriched in cell cycle and insulin-signaling pathways. Previous literature suggests that miRNA, together with transcriptional factors (i.e., c-MYC, E2F, or p53), coordinately control the levels of multiple cell-cycle regulators and cell proliferation (O'Donnell et al., 2005; Bueno and Malumbres, 2011). Among the several miRNA, special attention has been given to miR-148a. This miRNA regulates the expression of genes involved in the cell cycle, such as M-phase inducer phosphatase 2 (CDC25B; Liffers et al., 2011), as we also identified in this study (Supplemental Table S1, https://doi.org/10.3168/jds.2020-18283). This finding is also supported by Shi et al. (2015), who revealed that the cell-cycle pathway is associated with miR-148a.

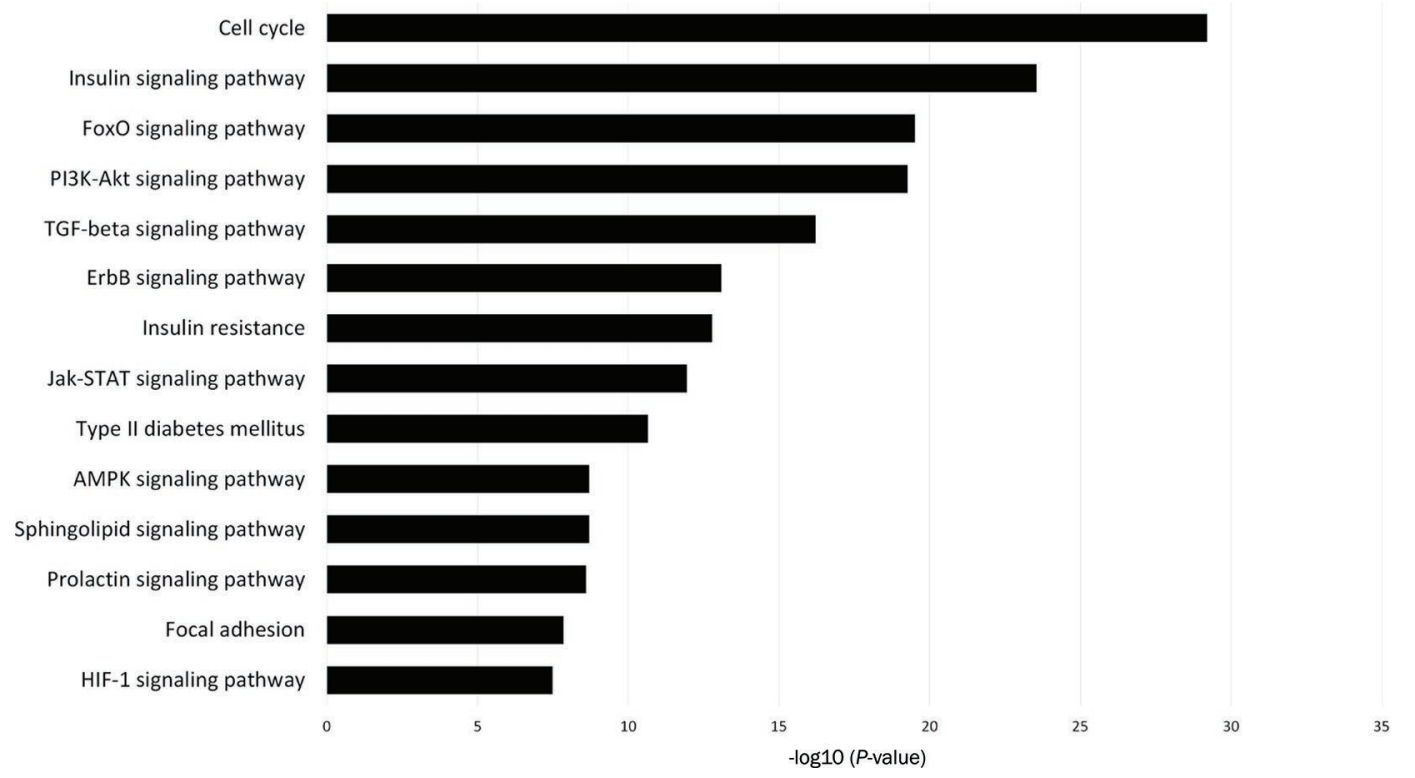

Figure 5. Target prediction and pathway enrichment. Pathway enrichment analysis for genes regulated by differentially expressed microRNA (DE-miRNA). Genes regulated by DE-miRNA were retrieved and enriched in Kyoto encyclopedia of genes and genomes. The top 15 significantly enriched items are shown. The statistical significance level ( $P$-value) was a negative log base 10 transformed. 
In dairy cows, the cell cycle was also identified by gene expression analyses in the liver to be negatively affected by overnutrition prepartum (Khan et al., 2015).

In the current study, the predicted results showed that miR-30a target genes are associated with insulin resistance, and interleukin (IL)-6 family signaling, as well as adipocytokine and leptin signaling pathways. The miR-30 family (namely, miR-30a, b, c, d, and e) is an important member due to its role in tissue development and disease pathogenesis (Mao et al., 2018). Enforced expression of miR-30a in adipose tissue was demonstrated to increase insulin sensitivity and to exert anti-inflammatory actions in mice (Koh et al.,
2018). The nadir we observed in serum miR-30a around calving might be related to the well-known decrease in insulin sensitivity and inflammation at that time. However, the concentrations in the circulation might not allow for assessing the situation at the tissue level. Considering that miR-148a was reported to be positively associated with adipocyte differentiation in vitro (Shi et al., 2015), our finding of the relatively lowest values around calving in dairy cows seem to be in line with low or absent adipogenesis peripartum. However, the group by time interaction we observed for miR$148 \mathrm{a}$ is difficult to interpret, and it is also not known whether serum miR-148a might have potential as an
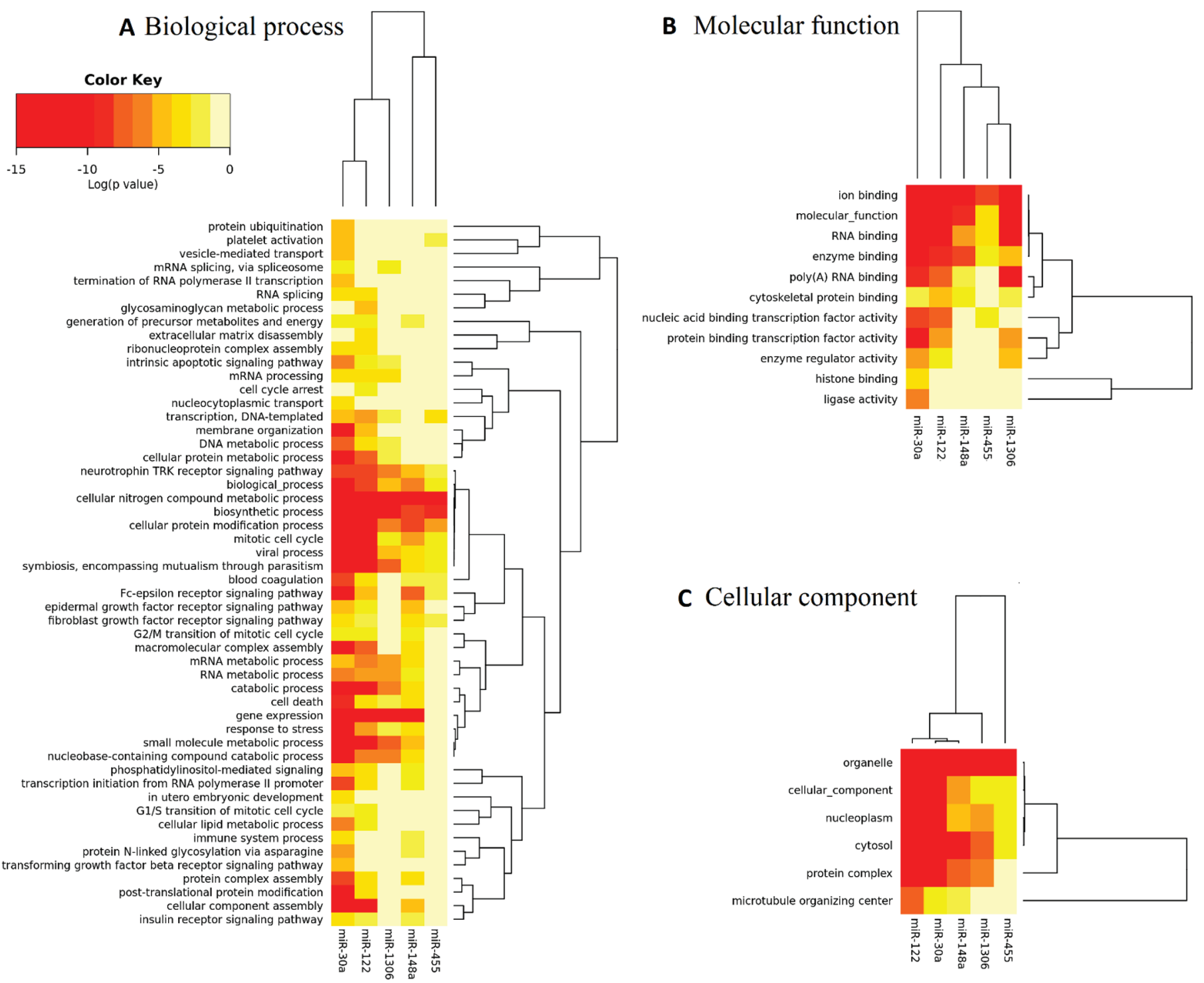

Figure 6. Heatmap of significant differentially expressed microRNA (DE-miRNA) and relative Kyoto encyclopedia of genes and genomes activated pathways at 3 levels: (A) biological process, (B) molecular function, and (C) cellular component. The color in the heatmap represents the significance levels ( $\log P$-values) between each miRNA and every pathway. The $P$-value threshold was 0.01 , using Fisher's Exact test. 
indicator for metabolic disorders other than cancer in any species.

In the current study, strong positive correlations were found among the serum levels of miR-30a with miR-122 and miR-455-5p, which is consistent with the results from the miRNA-target interactions. These miRNA share targets such as SHOC2 (leucine-rich repeat scaffold protein), SOCS3 (suppressor of cytokine signaling 3), and PDE7A (phosphodiesterase 7A), pointing to a link with inflammatory-related signaling functions.

In early lactation, labile protein reserves mainly from skeletal muscle are used to provide AA for direct oxidation, gluconeogenesis, and milk protein synthesis of dairy cows (Kuhla et al., 2011; Sadri et al., 2016). According to our enrichment analysis, miR-122 was mainly engaged in glucose (i.e., gluconeogenesis, glycolysis) and AA metabolic pathway by targeting $A L$ DOA (Aldolase A) and P4HA1 (Prolyl 4-Hydroxylase Subunit Alpha 1) genes. Aldolase A, which is a direct target of miR-122 in liver cells (Fabani and Gait, 2008), is a key enzyme in the fourth step of glycolysis and in the reverse pathway gluconeogenesis. Furthermore, miR-122 regulates $P 4 H A 1$ by repressing the expression of its mRNA (Esau et al., 2006; Li et al., 2013). The function of miR-122 may, however, also be tied to fatty acid metabolism. It has been reported that miR-122 is primarily expressed in the liver (Lewis and Jopling, 2010) and that it may modulate hepatic fatty acid metabolism by targeting the key lipogenic enzymes as indicated by a mouse model (Li et al., 2009). In the current study, circulating miR-122 was downregulated in early lactation compared with late gestation. Elevated lipolysis, indicated by increasing serum NEFA levels in early lactation, was observed in this study (Schuh et al., 2019). We speculate that this downregulation of circulating miR-122 might mirror the increase in lipolysis and the concomitant increase in fatty acid oxidation rates in early lactation. Moreover, it has been found that miR-122 promotes cholesterol synthesis and lipoprotein secretion in the liver (Esau et al., 2006). It is known that an imbalance between lipomobilization and hepatic lipid disposal leads to fatty liver and ketosis in early lactation (Drackley, 1999). The reduced circulating cholesterol observed after miR-122 inhibition by antisense oligonucleotide may be reflected by reductions in both the high-density and low-density

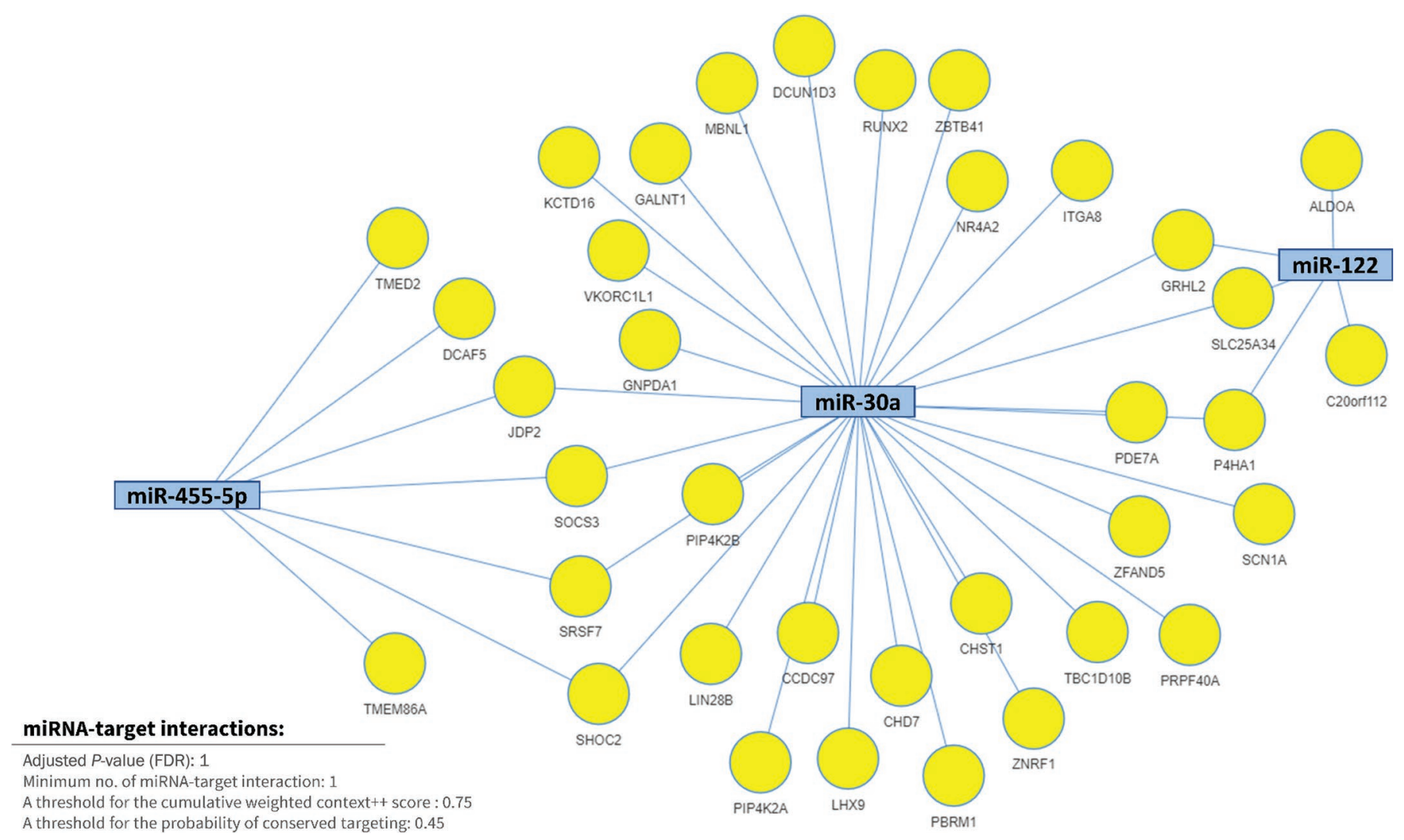

Figure 7. Visualization of resulting microRNA (miRNA)-target interactions as a network. Among the differentially expressed (DE)-miRNA, target interactions among miR-122, miR-30a, and miR-455-5p with at least 2 target interactions were identified. Source nodes (single miRNA) are blue circles, and target nodes (mRNA) are yellow circles. 
A

KEGG

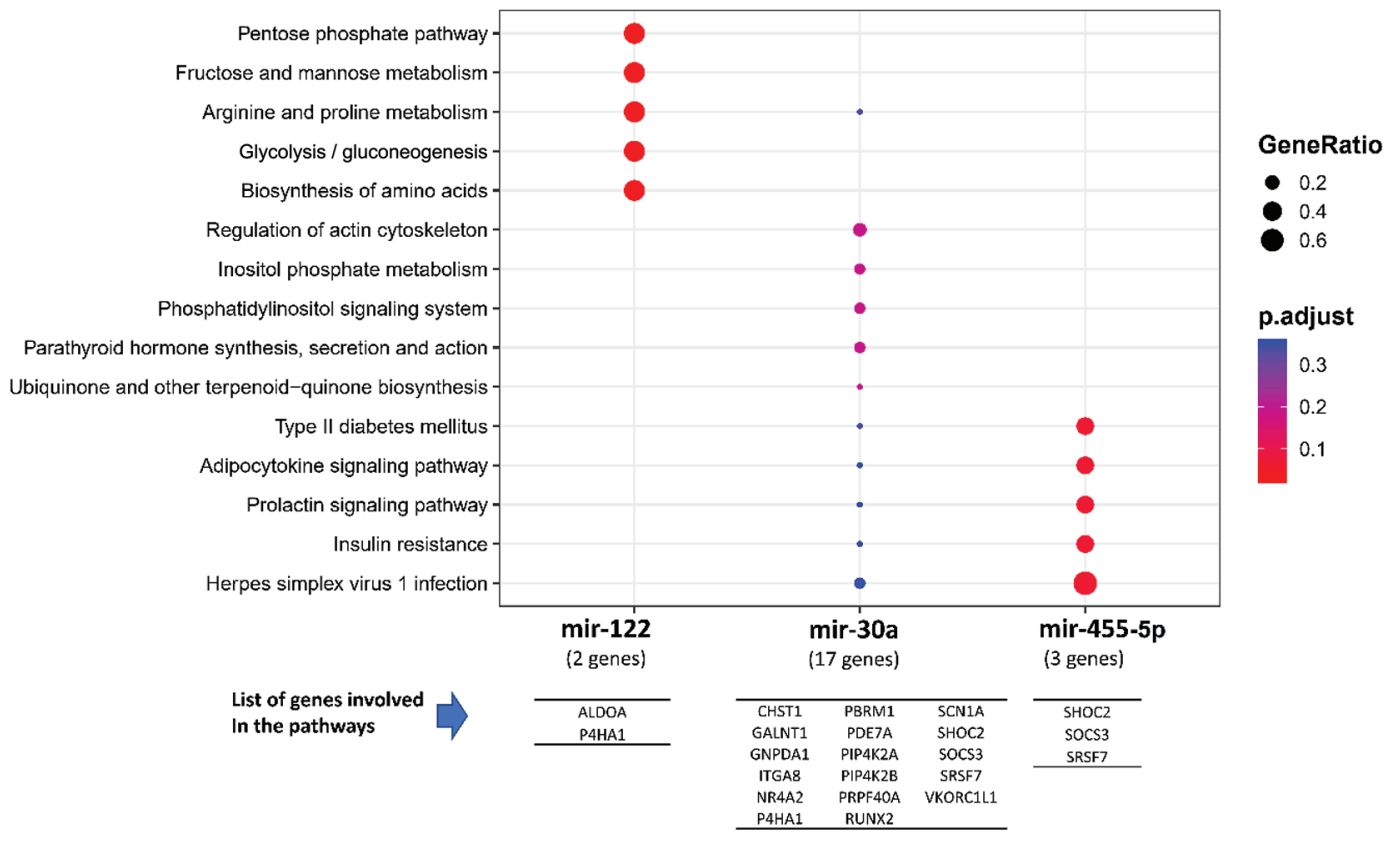

B

Reactome

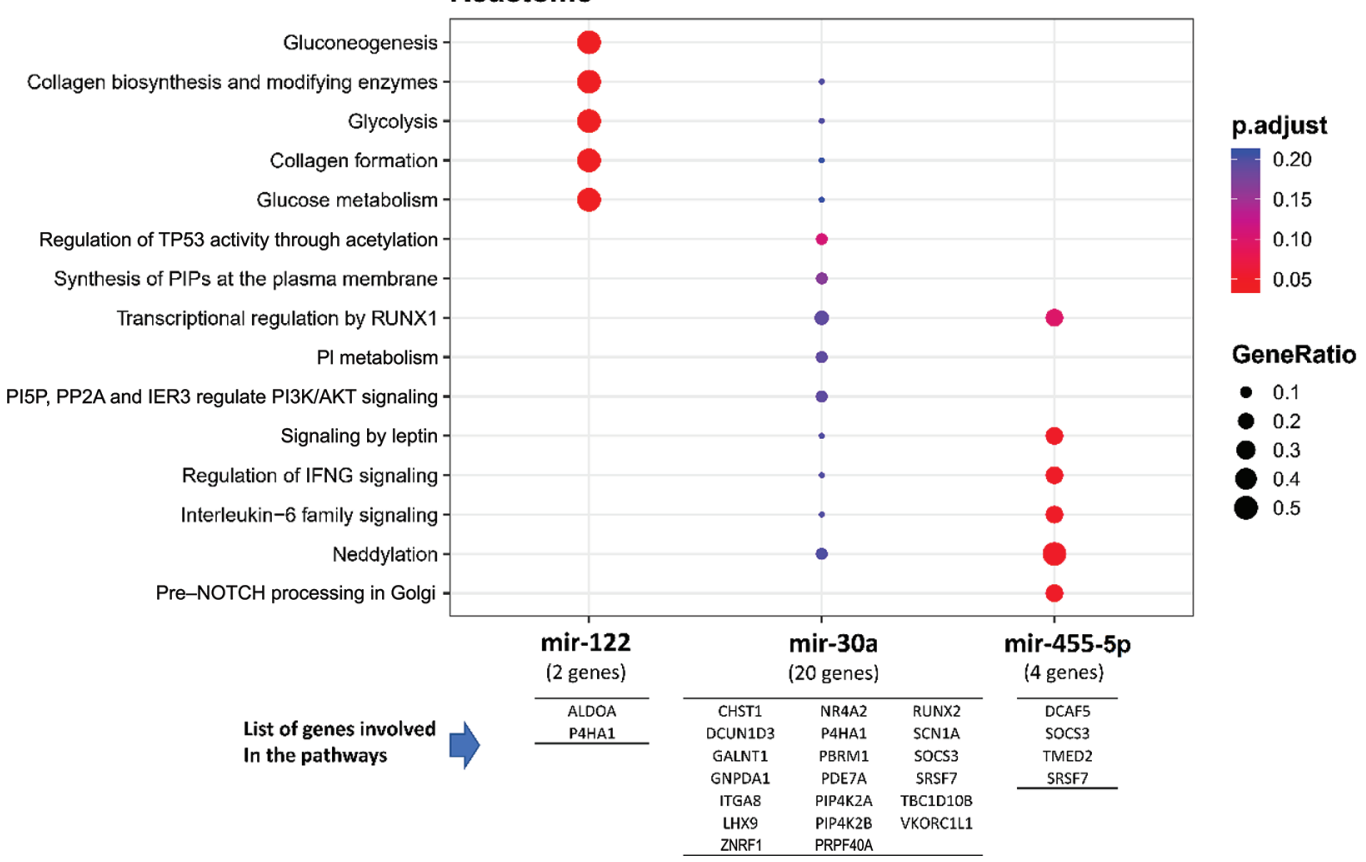

Figure 8. Dot plot of functional enrichment analysis for target genes of selected microRNA (miRNA) resulting from the enrichment analysis. The y-axis reports the annotation categories (A) Kyoto encyclopedia of genes and genomes (KEGG) pathways and (B) Reactome pathways, and the $\mathrm{x}$-axis reports the selected miRNA. The color of the dots represents the adjusted $P$-values (false discovery rate), whereas the size of the dots represents gene ratio (i.e., the number of miRNA targets found enriched in each category over the number of total genes associated with that category).

lipoprotein fractions (Esau et al., 2006). These findings suggest that the downregulation of circulating miR-122 may be functionally linked to liver dysfunction in dairy cows during early lactation.
Although we found little differences in the serum miRNA in over-conditioned compared with normalconditioned cows, we demonstrated the presence of specific circulating miRNA with potential importance 
during the transition period for dairy cows. Extending future work from pooled to individual samples may give rise to identifying further miRNA in this context and boost the characterization of interindividual variation.

\section{CONCLUSIONS}

We found only subtle differences in circulating miRNA of dairy cows that were normal or over conditioned, and thus no prospect of potential biomarkers could be derived. Longitudinal changes in circulating miRNA profiles were observed regardless of body condition and most of the DE-miRNA (miR-148a, miR-122, miR-30a, miR-450b, miR-455-5p) were downregulated directly after calving. These miRNA were found to be involved in biological pathways related to cell cycle and insulin signaling as well as glucose and lipid metabolism during the transition period. The information about the circulating miRNA in transition cows extends our knowledge to the level of miRNA and, by the pathways assigned, confirms the knowledge from classical as well as omics analyses.

\section{ACKNOWLEDGMENTS}

This study was supported by the PPP Program for Project-related Personal Exchange, promoting international mobility of researchers, financed by the Joint Mobility Program of the German Academic Exchange Service (DAAD, Bonn) and the Italian Ministry of Education, Universities and Research (MIUR, Rome). The authors thank all co-workers at the Educational and Research Centre for Animal Husbandry, Hofgut Neumuehle who were involved in the animal trial. Special gratitude is dedicated to Inga Hofs (Institute of Animal Science, Physiology and Hygiene Unit, University of Bonn, Germany) as well as Frieder Hadlich (Leibniz-Institute for Farm Animal Biology, Institute for Genome Biology, Germany) for their excellent laboratory assistance. The authors also express their appreciation to Georg Dusel (University of Applied Sciences Bingen, Germany) and Christiane Urh (University of Bonn, Germany) for their help in the animal study and the qPCR analyses, respectively. K. Schuh was a recipient of a scholarship from the H. Wilhelm Schaumann Foundation (Hamburg, Germany). The authors confirm that no conflict of interest exists.

\section{REFERENCES}

Babraham Bioinformatics. 2018 FastQC. Version 0.11.5. Accessed Jul. 16, 2020. http://www.bioinformatics.babraham.ac.uk/projects/ fastqc/.
Bartel, D. P. 2004. MicroRNAs: Genomics, biogenesis, mechanism, and function. Cell 116:281-297. https://doi.org/10.1016/S0092 $-8674(04) 00045-5$.

Bueno, M. J., and M. Malumbres. 2011. MicroRNAs and the cell cycle. Biochim. Biophys. Acta 1812:592-601. https://doi.org/10.1016/j .bbadis.2011.02.002.

Chen, X., Y. Ba, L. Ma, X. Cai, Y. Yin, K. Wang, J. Guo, Y. Zhang, J. Chen, X. Guo, Q. Li, X. Li, W. Wang, Y. Zhang, J. Wang, X. Jiang, Y. Xiang, C. Xu, P. Zheng, J. Zhang, R. Li, H. Zhang, X. Shang, T. Gong, G. Ning, J. Wang, K. Zen, J. Zhang, and C. Y. Zhang. 2008. Characterization of microRNAs in serum: a novel class of biomarkers for diagnosis of cancer and other diseases. Cell Res. 18:997-1006. https://doi.org/10.1038/cr.2008.282.

Coenen-Stass, A. M. L., I. Mager, and M. J. A. Wood. 2015. Extracellular microRNAs in membrane vesicles and non-vesicular carriers. Exp. Suppl. 106:31-53. https://doi.org/10.1007/978-3-0348-0955-9 $\_2$.

Drackley, J. K. 1999. Biology of dairy cows during the transition period: The final frontier? J. Dairy Sci. 82:2259-2273. https://doi .org/10.3168/jds.S0022-0302(99)75474-3.

Drackley, J. K., H. M. Dann, G. N. Douglas, N. A. J. Guretzky, N. B. Litherland, J. P. Underwood, and J. J. Loor. 2005. Physiological and pathological adaptations in dairy cows that may increase susceptibility to periparturient diseases and disorders. Ital. J. Anim. Sci. 4:323-344. https://doi.org/10.4081/ijas.2005.323.

Edmonson, A. J., I. J. Lean, L. D. Weaver, T. Farver, and G. Webster. 1989. A body condition scoring chart for Holstein dairy cows. J. Dairy Sci. 72:68-78. https://doi.org/10.3168/jds.S0022 -0302(89)79081-0.

Esau, C., S. Davis, S. F. Murray, X. X. Yu, S. K. Pandey, M. Pear, L. Watts, S. L. Booten, M. Graham, R. McKay, A. Subramaniam, S. Propp, B. A. Lollo, S. Freier, C. F. Bennett, S. Bhanot, and B. P. Monia. 2006. miR-122 regulation of lipid metabolism revealed by in vivo antisense targeting. Cell Metab. 3:87-98. https://doi.org/ 10.1016/j.cmet.2006.01.005.

Fabani, M. M., and M. J. Gait. 2008. miR-122 targeting with LNA/2'O-methyl oligonucleotide mixmers, peptide nucleic acids (PNA), and PNA-peptide conjugates. RNA 14:336-346. https://doi.org/ 10.1261/rna.844108.

Fan, Y., K. Siklenka, S. K. Arora, P. Ribeiro, S. Kimmins, and J. Xia. 2016. miRNet-dissecting miRNA-target interactions and functional associations through network-based visual analysis. Nucleic Acids Res. 44:W135-W141. https://doi.org/10.1093/nar/gkw288.

Friedländer, M. R., S. D. Mackowiak, N. Li, W. Chen, and N. Rajewsky. 2012. miRDeep2 accurately identifies known and hundreds of novel microRNA genes in seven animal clades. Nucleic Acids Res. 40:37-52. https://doi.org/10.1093/nar/gkr688.

Friendly, M. 2002. Corrgrams. Am. Stat. 56:316-324. https://doi.org/ $10.1198 / 000313002533$.

Gearhart, M. A., C. R. Curtis, H. N. Erb, R. D. Smith, C. J. Sniffen, L. E. Chase, and M. D. Cooper. 1990. Relationship of changes in condition score to cow health in Holsteins. J. Dairy Sci. 73:31323140. https://doi.org/10.3168/jds.S0022-0302(90)79002-9.

GfE (Society for Nutrition Physiology). 2001. Ausschuss für Bedarfsnormen der Gesellschaft für Ernährungsphysiologie. Nr. 8. Empfehlungen zur Energie- und Nährstoffversorgung der Milchkühe und Aufzuchtrinder (Recommendations of energy and nutrient supply for dairy cows and breeding cattle). Frankfurt am Main, Germany.

Ghaffari, M. H., A. Jahanbekam, H. Sadri, K. Schuh, G. Dusel, C. Prehn, J. Adamski, C. Koch, and H. Sauerwein. 2019. Metabolomics meets machine learning: Longitudinal metabolite profiling in serum of normal versus overconditioned cows and pathway analysis. J. Dairy Sci. 102:11561-11585. https://doi.org/10.3168/ jds.2019-17114.

Ghaffari, M. H., H. Sadri, K. Schuh, G. Dusel, C. Prehn, J. Adamski, C. Koch, and H. Sauerwein. 2020a. Alterations of the acylcarnitine profiles in blood serum and in muscle from periparturient cows at normal or elevated body condition. J. Dairy Sci. 103:4777-4794. https://doi.org/10.3168/jds.2019-17713. 
Ghaffari, M. H., K. Schuh, J. Kuleš, N. Guillemin, A. Horvatić, V. Mrljak, P. D. Eckersall, G. Dusel, C. Koch, H. Sadri, and H. Sauerwein. 2020b. Plasma proteomic profiling and pathway analysis of normal and over conditioned dairy cows during the transition from late pregnancy to early lactation. J. Dairy Sci. 103:4806-4821. https://doi.org/10.3168/jds.2019-17897.

Grummer, R. R. 1995. Impact of changes in organic nutrient metabolism on feeding the transition dairy cow. J. Anim. Sci. 73:28202833. https://doi.org/10.2527/1995.7392820x.

Hailay, T., M. Hoelker, M. Poirier, S. Gebremedhn, F. Rings, M. SaeedZidane, D. Salilew-Wondim, C. Dauben, E. Tholen, C. Neuhoff, K. Schellander, and D. Tesfaye. 2019. Extracellular vesicle-coupled miRNA profiles in follicular fluid of cows with divergent post-calving metabolic status. Sci. Rep. 9:12851. https://doi.org/10.1038/ s41598-019-49029-9.

Huang, Y., Y. X. Yan, W. C. Xv, G. Qian, C. J. Li, H. Q. Zou, and Y. Q. Li. 2018. A new insight into the roles of miRNAs in metabolic syndrome. BioMed Res. Int. 2018:7372636. https://doi.org/ $10.1155 / 2018 / 7372636$.

Ingvartsen, K. L. 2006. Feeding- and management-related diseases in the transition cow: Physiological adaptations around calving and strategies to reduce feeding-related diseases. Anim. Feed Sci. Technol. 126:175-213. https://doi.org/10.1016/j.anifeedsci.2005 .08 .003 .

Khan, M. J., C. B. Jacometo, M. Vailati Riboni, E. Trevisi, D. E. Graugnard, M. N. Corrêa, and J. J. Loor. 2015. Stress and inflammatory gene networks in bovine liver are altered by plane of dietary energy during late pregnancy. Funct. Integr. Genomics 15:563-576. https://doi.org/10.1007/s10142-015-0443-2.

Koh, E. H., N. Chernis, P. K. Saha, L. Xiao, D. A. Bader, B. Zhu, K. Rajapakshe, M. P. Hamilton, X. Liu, D. Perera, X. Chen, B. York, M. Trauner, C. Coarfa, M. Bajaj, D. D. Moore, T. Deng, S. E. McGuire, and S. M. Hartig. 2018. miR-30a remodels subcutaneous adipose tissue inflammation to improve insulin sensitivity in obesity. Diabetes 67:2541-2553. https://doi.org/10.2337/db17-1378.

Komaragiri, M. V. S., D. P. Casper, and R. A. Erdman. 1998. Factors affecting body tissue mobilization in early lactation dairy cows. 2. Effect of dietary fat on mobilization of body fat and protein. J. Dairy Sci. 81:169-175. https://doi.org/10.3168/jds.S0022 -0302(98)75564-X

Kuhla, B., G. Nürnberg, D. Albrecht, S. Görs, H. M. Hammon, and C. C. Metges. 2011. Involvement of skeletal muscle protein, glycogen, and fat metabolism in the adaptation on early lactation of dairy cows. J. Proteome Res. 10:4252-4262. https://doi.org/10.1021/ pr200425h.

Laterza, O. F., L. Lim, P. W. Garrett-Engele, K. Vlasakova, N. Muniappa, W. K. Tanaka, J. M. Johnson, J. F. Sina, T. L. Fare, F. D. Sistare, and W. E. Glaab. 2009. Plasma MicroRNAs as sensitive and specific biomarkers of tissue injury. Clin. Chem. 55:1977-1983. https://doi.org/10.1373/clinchem.2009.131797.

Lewis, A. P., and C. L. Jopling. 2010. Regulation and biological function of the liver-specific miR-122. Biochem. Soc. Trans. 38:15531557. https://doi.org/10.1042/BST0381553.

Lewis, B. P., C. B. Burge, and D. P. Bartel. 2005. Conserved seed pairing, often flanked by adenosines, indicates that thousands of human genes are microRNA targets. Cell 120:15-20. https://doi .org/10.1016/j.cell.2004.12.035.

Li, J., M. Ghazwani, Y. Zhang, J. Lu, J. Li, J. Fan, C. R. Gandhi, and S. Li. 2013. miR-122 regulates collagen production via targeting hepatic stellate cells and suppressing P4HA1 expression. J. Hepatol. 58:522-528. https://doi.org/10.1016/j.jhep.2012.11.011.

Li, S., X. Chen, H. Zhang, X. Liang, Y. Xiang, C. Yu, K. Zen, Y. Li, and C. Y. Zhang. 2009. Differential expression of microRNAs in mouse liver under aberrant energy metabolic status. J. Lipid Res. 50:1756-1765. https://doi.org/10.1194/jlr.M800509-JLR200.

Liffers, S. T., J. B. Munding, M. Vogt, J. D. Kuhlmann, B. Verdoodt, S. Nambiar, A. Maghnouj, A. Mirmohammadsadegh, S. A. Hahn, and A. Tannapfel. 2011. MicroRNA-148a is down-regulated in human pancreatic ductal adenocarcinomas and regulates cell survival by targeting CDC25B. Lab. Invest. 91:1472-1479. https://doi.org/ 10.1038/labinvest.2011.99.
Lim, L. P., N. C. Lau, P. Garrett-Engele, A. Grimson, J. M. Schelter, J. Castle, D. P. Bartel, P. S. Linsley, and J. M. Johnson. 2005. Microarray analysis shows that some microRNAs downregulate large numbers of target mRNAs. Nature 433:769-773. https://doi .org/10.1038/nature03315.

Livak, K. J., and T. D. Schmittgen. 2001. Analysis of relative gene expression data using real-time quantitative PCR and the $2(\mathrm{~T})$ (-Delta Delta C) method. Methods 25:402-408. https://doi.org/10 $.1006 /$ meth.2001.1262.

Mackowiak, S. D. 2011. Identification of novel and known miRNAs in deep-sequencing data with miRDeep2. Curr. Protoc. Bioinformatics 36:12.10.1-12.10.15. https://doi.org/10.1002/0471250953 .bi1210s36.

Manning, P., P. E. Munasinghe, J. B. Papannarao, A. R. Gray, W. Sutherland, and R. Katare. 2019. Acute weight loss restores dysregulated circulating microRNAs in individuals who are obese. J. Clin. Endocrinol. Metab. 104:1239-1248. https://doi.org/10.1210/ jc.2018-00684.

Mansouryar, M., H. Mirzaei-Alamouti, M. Dehghan Banadaky, H. Sauerwein, M. Mielenz, and M. O. Nielsen. 2018. Short communication: Relationship between body condition score and plasma adipokines in early-lactating Holstein dairy cows. J. Dairy Sci. 101:8552-8558. https://doi.org/10.3168/jds.2017-14122.

Mao, L., S. Liu, L. Hu, L. Jia, H. Wang, M. Guo, C. Chen, Y. Liu, and L. Xu. 2018. miR-30 family: A promising regulator in development and disease. BioMed Res. Int. 2018:9623412. https://doi.org/10 $.1155 / 2018 / 9623412$

McCarthy, D. J., Y. S. Chen, and G. K. Smyth. 2012. Differential expression analysis of multifactor RNA-Seq experiments with respect to biological variation. Nucleic Acids Res. 40:4288-4297. https:// doi.org/10.1093/nar/gks042.

Mizuno, H., A. Nakamura, Y. Aoki, N. Ito, S. Kishi, K. Yamamoto, M. Sekiguchi, S. Takeda, and K. Hashido. 2011. Identification of muscle-specific MicroRNAs in serum of muscular dystrophy animal models: Promising novel blood-based markers for muscular dystrophy. PLoS One 6:e18388. https://doi.org/10.1371/journal .pone.0018388.

O'Donnell, K. A., E. A. Wentzel, K. I. Zeller, C. V. Dang, and J. T. Mendell. 2005. c-Myc-regulated microRNAs modulate E2F1 expression. Nature 435:839-843. https://doi.org/10.1038/ nature03677.

Pires, J. A. A., C. Delavaud, Y. Faulconnier, D. Pomies, and Y. Chilliard. 2013. Effects of body condition score at calving on indicators of fat and protein mobilization of periparturient Holstein-Friesian cows. J. Dairy Sci. 96:6423-6439. https://doi.org/10.3168/jds.2013 $-6801$.

Reid, I. M., C. J. Roberts, R. J. Treacher, and L. A. Williams. 1986. Effect of body condition at calving on tissue mobilization, development of fatty liver and blood-chemistry of dairy-cows. Anim. Prod. 43:7-15. https://doi.org/10.1017/S0003356100018298.

Rico, J. E., V. V. R. Bandaru, J. M. Dorskind, N. J. Haughey, and J. W. McFadden. 2015. Plasma ceramides are elevated in overweight Holstein dairy cows experiencing greater lipolysis and insulin resistance during the transition from late pregnancy to early lactation. J. Dairy Sci. 98:7757-7770. https://doi.org/10.3168/jds.2015 $-9519$.

Robinson, M. D., D. J. McCarthy, and G. K. Smyth. 2010. edgeR: A Bioconductor package for differential expression analysis of digital gene expression data. Bioinformatics 26:139-140. https://doi.org/ 10.1093/bioinformatics/btp616.

Roche, J. R., N. C. Friggens, J. K. Kay, M. W. Fisher, K. J. Stafford, and D. P. Berry. 2009. Invited review: Body condition score and its association with dairy cow productivity, health, and welfare. J. Dairy Sci. 92:5769-5801. https://doi.org/10.3168/jds.2009-2431.

Roche, J. R., K. A. Macdonald, K. E. Schutz, L. R. Matthews, G. A. Verkerk, S. Meier, J. J. Loor, A. R. Rogers, J. McGowan, S. R. Morgan, S. Taukiri, and J. R. Webster. 2013. Calving body condition score affects indicators of health in grazing dairy cows. J. Dairy Sci. 96:5811-5825. https://doi.org/10.3168/jds.2013-6600.

Sadri, H., F. Giallongo, A. N. Hristov, J. Werner, C. H. Lang, C. Parys, B. Saremi, and H. Sauerwein. 2016. Effects of slow-release 
urea and rumen-protected methionine and histidine on mammalian target of rapamycin (mTOR) signaling and ubiquitin proteasome-related gene expression in skeletal muscle of dairy cows. J. Dairy Sci. 99:6702-6713. https://doi.org/10.3168/jds.2015-10673.

Schröder, U. J., and R. Staufenbiel. 2006. Invited review: Methods to determine body fat reserves in the dairy cow with special regard to ultrasonographic measurement of backfat thickness. J. Dairy Sci. 89:1-14. https://doi.org/10.3168/jds.S0022-0302(06)72064-1.

Schuh, K., H. Sadri, S. Häussler, L. A. Webb, C. Urh, M. Wagner, C. Koch, J. Frahm, S. Dänicke, G. Dusel, and H. Sauerwein. 2019. Comparison of performance and metabolism from late pregnancy to early lactation in dairy cows with elevated v. normal body condition at dry-off. Animal 13:1478-1488. https://doi.org/10.1017/ S1751731118003385.

Shi, C., M. Zhang, M. L. Tong, L. Yang, L. X. Pang, L. Chen, G. F. Xu, X. Chi, Q. Hong, Y. H. Ni, C. B. Ji, and X. R. Guo. 2015.
miR-148a is associated with obesity and modulates adipocyte differentiation of mesenchymal stem cells through Wnt signaling. Sci. Rep. 5:9930. https://doi.org/10.1038/srep09930.

Vlachos, I. S., K. Zagganas, M. D. Paraskevopoulou, G. Georgakilas, D. Karagkouni, T. Vergoulis, T. Dalamagas, and A. G. Hatzigeorgiou . 2015. DIANA-miRPath v3. 0: Deciphering microRNA function with experimental support. Nucleic Acids Res. 43:W460-466. https://doi.org/10.1093/nar/gkv403.

Ylioja, C. M., M. M. Rolf, L. K. Mamedova, and B. J. Bradford. 2019. Associations between body condition score at parturition and microRNA profile in colostrum of dairy cows as evaluated by paired mapping programs. J. Dairy Sci. 102:11609-11621. https:// doi.org/10.3168/jds.2019-16675.

Yu, G., L. G. Wang, Y. Han, and Q. Y. He. 2012. clusterProfiler: An $\mathrm{R}$ package for comparing biological themes among gene clusters. OMICS 16:284-287. https://doi.org/10.1089/omi.2011.0118. 